Werke und soll einen ausgedehnten Briefwechsel mit in- und ausländischen Gelehrten unterhalten haben, in Zürich mit Dr. Kaspar Wolf und Wilhelm Stucki, der eine Laudatio auf Pfändler verfaßt habe. Pfändlers Sohn, ebenfalls Arzt und Landammann, Heinrich, dessen Basler Doktordiplom sich unter den Tschudi-Akten in Glarus befindet, verfaßte nach Husner zwei

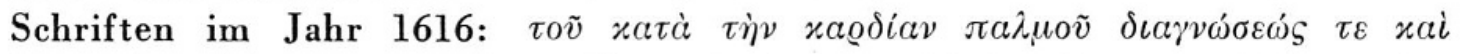

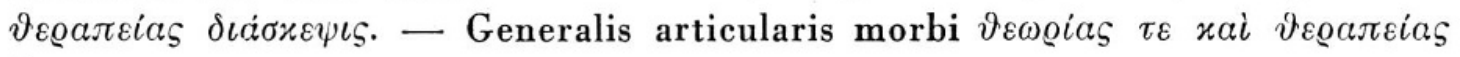
$\delta\llcorner a \gamma \varrho a p \dot{\eta}$.

Mit dieser Arbeit Hoffmanns hat nicht nur die Glarner Kulturgeschichte, sondern auch die Schweizer Medizinhistorie eine sehr erfreuliche Bereicherung erfahren.

B. Milt.

\title{
Gustav Senn
}

9. November $1875-10$. Juli 1945

Mitten aus vielseitiger Tätigkeit heraus ist uns Gustav Senn, Ordinarius für Botanik an der Universität Basel, kurz vor Vollendung seines 70. Altersjahres durch einen Herzschlag entrissen worden. Die Schweiz. Gesellschaft für Geschichte der Medizin und der Naturwissenschaften verliert in dem Verstorbenen eines ihrer aktivsten und treuesten Mitglieder. War es doch Gustav Senn, welcher mit Arnold Klebs, H. E. Sigerist u. a. zusammen vor bald 25 Jahren die Gründung unserer Gesellschaft mit aller Energie betrieb und sich mit der ihm eigenen Begeisterung für die Entwicklung der Gesellschaft einsetzte, die er lange Jahre als Präsident betreute. - Mit großer Sympathie und mannigfacher Ermunterung hatte Senn auch das Erscheinen unserer Vierteljahresschrift, die Schöpfung seines unvergessenen Freundes J. Strohl, den «Gesnerus» begrüßt, bei dessen Namengebung Senn Pate gestanden hatte.

Von Anfang an hat sich Senn, in glücklichster Weise seiner ausgesprochenen humanistischen Neigung und Veranlagung folgend, dem einen großen Thema, der Erforschung der antiken Biologie, zugewandt, eine Aufgabe, welche ihn durch sein ganzes weiteres, leider so jäh zum Abschluß gelangtes Leben begleiten sollte. In den Mittelpunkt seiner biologiehistorischen Studien, welche er bei aller sonstigen Belastung und zeit- 
weisen Überlastung mit großer Ausdauer und im stillen passioniert verfolgte, stellte er die große Gestalt Theophrasts von Eresos, des "Vaters der wissenschaftlichen Botanik», jenes größten Schülers des Aristoteles, welcher, als echter Schüler, in Forschungsziel und Methode über seinen Lehrer hinausgelangte. Dies zu zeigen, galt Senn's früh als wesentlich erkanntes und durch sorgfältige Analyse des einschlägigen antiken Schrifttums zu erreichendes Bestreben. In unentwegter philologischer und textkritischer Kleinarbeit verfolgte Senn sein großes Telos, welches er über aller gebotenen Akribie nie aus den Augen verlor: Theophrast als geistesmächtigsten Träger der Antike (neben Aristoteles) jener im Werden begriffenen Wissenschaft darzustellen, welche uns heute als induktive Naturforschung so selbstverständlich geworden ist. War es doch Senn von allem Anfang an nicht nur daran gelegen, die vielen dunklen Stellen eines durch Lücken und Einschiebungen verderbten Textes zu erschließen, - dies ergab sich als Resultat geduldigster Kleinarbeit, zu welcher Senn dank seiner philologischen Ader durchaus fähig war, von selbst - sondern sein Bemühen galt der großen Aufgabe, angeregt durch das ähnliche Ziele verfolgende Buch Werner Jaegers über Aristoteles (1923), auf Grund stil- und textkritischer Untersuchungen den Entwicklungsgang der Werke und damit gleichzeitig den geistigen Weg Theophrasts als einen vom Platonismus zur induktiven Naturforschung fortschreitenden und erst im höheren Alter erreichten aufzuzeigen. Als erste Frucht dieser Bemühungen erschien Senns bedeutendes mit dem medizinischen Ehrendoktor der Universität Bern ausgezeichnetes Werk: «Die Entwicklung der biologischen Forschungsmethode in der Antike und ihre grundsätzliche Förderung durch Theophrast von Eresos» (1933), erschienen als Band 8 der «Veröffentlichungen der Schweiz. Geschichte der Medizin und der Naturwissenschaften.

Zwölf Jahre sind seither vergangen, zwölf Jahre angestrengtester weiterer Bearbeitung seines großen Themas, wovon zahlreiche Einzeluntersuchungen, von denen ich nur einige der letzten nennen möchte, aufschlußreiche Kunde gaben: «Über die Eichengallen Theophrasts» (1943) «Über den Weinbau im antiken Griechenland» (1944), «Theophrast und Descartes» (1945), «Konstanz und Variabilität der Species bei Aristoteles und Theophrast» (1945). Sie alle zeigten, mit welcher Sorgfalt, Umsicht und leidenschaftlicher Intensität Senn im Verborgenen am Werk arbeitete. Eine neue Synthes sollte bisher Erreichtes und Erstrebtes zusammenfassen. Diese Zusammenschau hoffte er, durch die bevorstehende 
Emeritierung von beruflicher Arbeit entlastet, in einigen Jahren leisten zu können. Noch standen umfangreichere Vorarbeiten in Aussicht. Sollte ihm auch noch jene Reise nach Assos in Kleinasien (dem fruchtbaren Studienaufenthalt des Aristoteles) und nach Eresos auf Mytilene (Lesbos) gelingen, von welcher er entscheidende Klärung botanischer und anderer theophrasteischer Fragen erhoffen durfte? Der unerbittliche Tod machte die Ausführung dieser wie eine verheißungsvolle Nachkriegshoffnung gelegentlich hell aufleuchtende Aussicht in die Ferne zunichte. Statt eines krönenden Abschlusses bleibt ein Torso, bleiben die Spuren unendlicher Bemühung - aber es fehlt der Schlußstein zum vollendeten Werk. Doch selbst die Fragmente seiner literarischen Hinterlassenschaft und eine als Basler Rektoratsprogramm fast fertig ausgearbeitete Darstellung von Theophrasts Werk werden der Biologiegeschichte wertvollste neue Aufschlüsse bringen. Aber wie vermöchten wir unser tiefstes Bedauern zu unterdrücken darüber, daß es Senn nicht mehr vergönnt war, das weitgesteckte Ziel seiner biologiegeschichtlichen Studien, eine umfassende Analyse der Werke Theophrasts und seines wissenschaftsgeschichtlichen Standortes, ausgeführt mit der Senn eigenen Gründlichkeit und Durchdachtheit, der Nachwelt zu hinterlassen. Senn war sich wohl bewußt, daß die Durcharbeitung Theophrasts in dem von ihm beabsichtigten weitgespannten Rahmen eine mehr wie volle Lebensarbeit bedeutete - aber den Weg dazu hatte er gezeigt und eine mächtige Wegstrecke zum Ziel selbst zurückgelegt. Andern wird nun die Aufgabe gestellt sein, den so klar und deutlich gesetzten Spuren zu folgen.

Senn hatte auf die im September dieses Jahres in Fribourg stattfindende Tagung unserer Gesellschaft, welche als Ehrung zu seinem 70. Geburtstag gedacht war, und zu der wir die antike Biologie als Thema eigens gewählt hatten, ein sein Forschen zusammenfassendes Referat über Theophrast versprochen. Leider sollte es ihm nicht mehr vergönnt sein, diesen Rechenschaftsbericht über seine Theophrastforschung vor festlicher Versammlung abzulegen. Auch die anläßlich seines 70. Geburtstages geplante Ehrung, ihm als Dank für seine großen Verdienste um unsere Gesellschaft die Ehrenmitgliedschaft der Schweiz. Gesellschaft für Geschichte der Medizin und der Naturwissenschaften zu verleihen, durfte er nicht mehr erleben.

In tiefem Schmerz nehmen wir an dem schweren Verlust, von dem wir alle so stark betroffen sind, Anteil. Mit Senn scheidet, man darf 
wohl sagen, die markanteste Gestalt aus unserm Kreise, welcher ihm so mannigfaltige und stets bereitwillig geleistete Anregung und Förderung verdankte, aus. Wir nehmen von Senn als einem vornehmen, zielbewußten, humorbegabten, gütigen und hilfbereiten Menschen und Freund Abschied, dessen ebenso arbeits- wie erfolgreiches Leben als verpflichtendes Erbe in uns weiterlebt.

H. Fischer. 